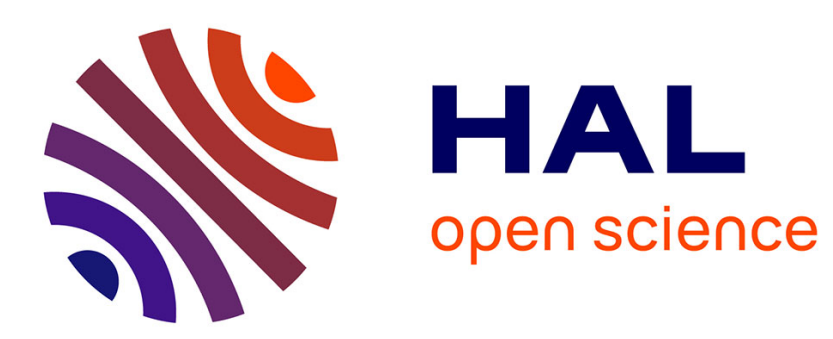

\title{
The Mechanism of Internal Friction Peak Associated with the Subboundaries
}

\author{
Z. Shen
}

\section{To cite this version:}

Z. Shen. The Mechanism of Internal Friction Peak Associated with the Subboundaries. Journal de Physique IV Proceedings, 1996, 06 (C8), pp.C8-341-C8-343. 10.1051/jp4:1996873 . jpa-00254681

\section{HAL Id: jpa-00254681 https://hal.science/jpa-00254681}

Submitted on 1 Jan 1996

HAL is a multi-disciplinary open access archive for the deposit and dissemination of scientific research documents, whether they are published or not. The documents may come from teaching and research institutions in France or abroad, or from public or private research centers.
L'archive ouverte pluridisciplinaire HAL, est destinée au dépôt et à la diffusion de documents scientifiques de niveau recherche, publiés ou non, émanant des établissements d'enseignement et de recherche français ou étrangers, des laboratoires publics ou privés. 


\title{
The Mechanism of Internal Friction Peak Associated with the Subboundaries
}

\author{
Z.C. Shen
}

\author{
International Center for Materials Physcics, Academia Sinica, 110145 Shengyang, China \\ Suzhou Professional University, Suzhou 215002, China
}

\begin{abstract}
It has been indicated that subboundaries apperar to have difficulty in sliding. This paper propose three mechanisms of the internal friction peak associated with subboundaries: diffusion creep, glide and climb of the jogged dislocations in subboundaries and the interaction of subboundaries and dislocations. We have analysed and calculated the internal friction

$$
Q^{-1}=\frac{\bar{n}_{1}^{2}}{\bar{n}_{0}} \frac{\mu \mathrm{s}}{\omega} \dot{\varepsilon} \frac{\mathrm{d} \ln V}{\mathrm{~d} \sigma} \cos \theta+\frac{2 \mathrm{ED}_{0} \mathrm{~b}^{3}}{\mathrm{~L}^{2} \mathrm{KT} \omega \ln (\mathrm{L} / \mathrm{b})} \exp \left(-\frac{\mathrm{U}}{\mathrm{KT}}\right) \text {. }
$$
\end{abstract}

\section{Introduction}

Early in 1955 , Friedel et al. ${ }^{[1]}$ had predicted in finely polygonized structures, near the melting point and in the cycle range, an internal friction peak was calculated to be about $600 \mathrm{C}^{[2]}$ (again for a frequency of $1 / 15 \mathrm{sec}^{-1}$ ). The relaxation processes can be thought of as producing broad internal friction peaks. Later, J. Woirgard, A - Riviere et al. ${ }^{[3.4]}$ had accomplished successful works and creative ideas at the high temperature damping in pure metals.

Recently, $\mathrm{S} \cdot \mathrm{C} \cdot \mathrm{Yan}$ and $\mathrm{T} \cdot \mathrm{S} \cdot \mathrm{K} \mathrm{e}^{\left[\hat{[5]}^{[j}\right.}$ reported that a systematic study of the internal friction associated with polygonization boundaries in $99.999 \% \mathrm{Al}$ and dilute $\mathrm{Al}-\mathrm{Cu}$ alloys has been made, such an internal friction peak was observed repeatedly. Internal friction is then measured at $396^{\circ} \mathrm{C}$ as a function of vibration frequency and a very high peak $\left(Q^{-1}=0.26\right)$ is observed around $8 \times 10^{-3} \mathrm{~Hz}$. On converting the frequency of measurement to $1 \mathrm{~Hz}$, the optimum temperature of this internal friction peak should be about $530^{\circ} \mathrm{C}$. Ke $\mathrm{e}^{[6]}$ also reported that the internal friction of cold - worked aluminum annealed just before recrystallization is extremely high, but drops abruptly to a much smaller value after recrystallization. The present experiment is definitely originating from a state of the specimen before recrystallization.

\section{The Mobility of Subboundaries}

Most modern structural theories of grain-boundaries (GB) and experiment observation clearly revealed a strong effect of grain boundaries structure on the mobility of grain boundaries. The rate of sliding strongly depends on the grain boundary misorientation at constant 
temperature and grain boundary shear stress. The random large angle boundaries were easy to slide, coincidence boundaries, near coincidence boundaries or subboundaries appear to have difficulty in sliding. ${ }^{[7.8]}$

The absorption of lattice dislocations which was taken as elementary process of $G B$ sliding. Transmission electron microscopy revealed a very distinct difference that high density of lattice dislocations were observed in the coincidence boundaries or subboundaries (SGB) while no lattice dislocation was observed in the random high angle boundaries. The absorption of lattice dislocations was supposed to be slow in the subboundaries. The gliding lattice dislocations are crossing through the subboundary, a step is produced at the subboundary surface. These obstacles make resistance to slip. Consequently, the dissipative energy of sliding of SGB is larger than that of sliding of GB. The internal friction peak associated with $\mathrm{SGB}$ is a very high peak.

\section{The Calculation of Internal Friction $Q^{-1}$}

For the face-centred-cubic metals with high stacking fault energy, dislocations are not widely split to be able to emit vacancies. We consider polygonized walls to act as sources or sinks of vacancies. In finely polygonized structures, there are many jogs per wall.

The chief difference between jogs and kinks is a difference in mobility; kinks can glide easily and are very high mobile, while jogs can move only by climb, which requires diffusion. These jogs in SGB may climb by absorbing or emitting vacancies.

The rate of diffusion creep $\dot{\varepsilon}$ is

$$
\dot{\varepsilon}=\frac{2 \mathrm{D}_{0} \mathrm{~b}^{3} \sigma}{\mathrm{L}^{2} \mathrm{KT} \ln (\mathrm{L} / \mathrm{b})} \exp \left(-\frac{\mathrm{U}}{\mathrm{KT}}\right)
$$

Where $\sigma$ is applied stress, $U$ is the active energy of self - diffusion, $L$ is the size of polygonized boundaries.

At high temperature and under small stress, the jogged dislocations climb to take place in the form of an "avalanche". The jogs climb by the nucleation of jog pairs and the propagation of single jogs along the dislocation line. The density of dislocations in subboundaries is

$$
\mathrm{N}=\frac{\theta}{\mathrm{Lb}}
$$

Where $\theta$ is the misorientation angle, $b$ is Burgers vector of SBD. The climb of a jogged dislocation is a guite specific case of dislocation motion that actually consists of mixed glide and climb. In the circumstances climb can be controlled by core diffusion.

The equilibrium spacing $\lambda$ of thermal jogs is given by $\mathrm{Eq}_{\mathrm{q}}(3)$,

$$
\lambda=a \exp \left(\frac{F_{j}}{K T}\right)
$$

The total dislocation velocity is ${ }^{[9]}$

$$
v\left(\sigma_{\mathrm{c}}\right)=\frac{4 \pi \mathrm{D}_{\mathrm{s}}}{\mathrm{h}} \exp \left(\frac{\sigma_{\mathrm{c}} \mathrm{bd} \lambda}{\mathrm{KI}}\right)
$$

Where $D_{s}$ is the atomic self-diffusion coefficient, $h$ is the height of the jog, $\lambda$ is the spacing 
of jogs, $d$ is the distance of jog moving after heat activation.

Under the climb driving force $\sigma_{\mathrm{c}}$ and applied stress $\sigma_{0} \mathrm{e}^{\mathrm{i \omega t}}$ of internal friction measurement, the dislocation velocity is

$$
v=\mathrm{V}\left(\sigma_{\mathrm{c}}\right)+\left(\frac{\mathrm{d} v}{\mathrm{~d} \sigma}\right)_{\sigma=\sigma_{0}} \mathrm{~s} \sigma_{0} \sin (\omega \mathrm{t}-\theta)
$$

Where $s$ is a coefficient, $\theta$ is the angle between dislocation velocity and stress.

The vibration energy $\triangle W$ is expended by the specimen in one cycle

$$
\Delta \mathrm{W}=\int_{0}^{\frac{2 \pi}{\omega}} \rho u b \sigma_{0} \sin \omega t \mathrm{dt}+\frac{2 \mathrm{ED}_{0} \mathrm{~b}^{3}}{\mathrm{KT} \ln (\mathrm{L} / \mathrm{b}) \mathrm{L}^{2} \omega} \exp \left(-\frac{\mathrm{U}}{\mathrm{KT}}\right)
$$

Where $\rho$ is the density of mobile dislocations. Consequently the internal friction

$$
\mathrm{Q}^{-1}=\frac{\overline{\mathrm{n}}_{\mathrm{t}}^{2}}{\overline{\mathrm{n}}_{\mathrm{p}}} \frac{\mu \mathrm{s}}{\omega} \dot{\varepsilon} \frac{\mathrm{dln} v}{\mathrm{~d} \sigma} \cos \theta+\frac{2 E D_{0} \mathrm{~b}^{3}}{\mathrm{~L}^{2} \mathrm{KT} \omega \ln (\mathrm{L} / \mathrm{b})} \exp \left(-\frac{\mathrm{U}}{\mathrm{KT}}\right)
$$

Where $\bar{n}_{p}$ is the average orientation factor of stretch stress, $\bar{n}_{t}$ is the average orientation factor of twist stress, $\dot{\varepsilon}$ is approximately constant, $\mu$ is the modulus of shear. We consider that some dislocations to be pinned at two end, another to move freely. We suppose dislocation segment of average length $L$, the damping coefficient of dislocation $B$, the relaxation time $\tau=\mathrm{BL}^{2} /$ $12 \gamma, \gamma$ is. the tension of dislocation line.

When $\tau$ is very latge,

$$
\mathrm{Q}^{-1} \simeq{\overline{\mathrm{n}_{t}^{2}}}_{\mathrm{n}_{\mathrm{p}}} \frac{\mu \mathrm{bd \lambda}}{\mathrm{KT}} \frac{\dot{\varepsilon}}{\omega}+\frac{2 \mathrm{ED}_{0} \mathrm{~b}^{3}}{\mathrm{~L}^{2} \mathrm{KT} \omega \ln (\mathrm{L} / \mathrm{b})} \exp \left(-\frac{\mathrm{U}}{\mathrm{KT}}\right)
$$

Let us estimate the first term of this equation: $\bar{n}_{\mathrm{t}}^{2} \sim 10^{-2}, \overline{\mathrm{n}}_{\mathrm{p}} \sim 10^{-1}, \mu \sim 4 \times 10^{10}, \mathrm{~b} \sim 2.5 \times$ $10^{-10}, \mathrm{~d} \sim 2.5 \times 10^{-10}, \lambda \sim 10^{-5}, \dot{\varepsilon} \sim 10^{-5}, \mathrm{k} \sim 1.38 \times 10^{-23}, \mathrm{~T} \sim 630, \omega \sim 8 \times 10^{-3}$ (in the international system of unit), $Q^{-1} \sim 10^{-1}$.

This theoretic result is quite in agreement with the relevant experimental result.

\section{References}

[1]J - Friedel et al. Acta. Metall. 3. 380(1955).

[2]A - S - Nowick and B. S. Berry," Anelastic Relaxation in Crystalline Solid, "Acadmic Press, INC. New York 460(1972)

[3]J - Woirgard, A - Riviere, and J - Fouquet, J. Physique 42,C5-407(1981);C - Esnouf and $G \cdot$ Fantozzi, ibid, $C 5-445$.

[4] M - L - No, C - Esnouf, J. San. Juan and G - Fantozzi, J. Physique, 46. C10-347 (1985).

[5]S $\cdot \mathrm{C} \cdot$ Yan and T $\cdot S \cdot$ Kê,Phys. Stat. Sol (a), 104,715(1987).

$[6] \mathrm{T} \cdot \mathrm{S} \cdot \mathrm{Kê}$, Trans. AIME 188,577,581(1950);

[7]T - Watanabe," Creep and Fracture of Engineering Materials and Structures" pub. Pineridge Press Limited,263. (1981),

$[8] P \cdot R \cdot$ Howell and $G \cdot L \cdot$ Dunlop, ibid. 127.

[9]J - Hirth and J - Lothe, "Theory of Dislocations" , Pub. McGraw-Hill, New York, 524 (1968). 